\title{
Theoretical substantiation choice of "comfortable" air temperature in industrial premises
}

\author{
Mikhail A. Ulchiekov ${ }^{1, *}$, and Elena E. Bulba ${ }^{1}$ \\ ${ }^{1}$ National Research Tomsk Polytechnic University, 634050 Tomsk, Russia
}

\begin{abstract}
In this paper solved the heat conduction problem for the system - the object of heat - insulation - environment (indoor air) considering natural convection. New variant substantiation of a choice the room temperature is proposed based on mathematical modelling.
\end{abstract}

\section{Introduction}

Energy saving is a priority problem in many sectors of the economy. The solution of global (essentially) energy saving task is only possible as a result of the decision of a large number (several hundreds) of specific targets to reduce energy costs in all industries and in the social sphere. One of these (belonging to the category of the most significant, perhaps) is the task of forming a comfortable [1] for the working climate of the production facilities. Most importantly, perhaps, the parameter that determines to a large extent the degree of "comfort" climate is air temperature TA. But now, the selection of this normative parameter $[2,3]$, is conducted on the basis of subjective feelings of the worker. But "comfortable" temperature in industrial premises can affect a large group of factors: the thermal insulation properties of clothing, work intensity, air circulation and others. Therefore, the definition of "comfortable" temperature of production facilities on the results of mathematical modeling "comfortable" temperature industrial premises is actual direction of research.

The purpose of this paper is mathematical modeling of the heat sink from the worker and the establishment of numerical values of $T_{A}$ that correspond to the conditions of "thermal comfort".

\section{Formulation of the problem}

It was assumed [1] that a healthy person the main part of the body temperature $T_{1}$ can fluctuate within a relatively small range of $35.5^{\circ} \mathrm{C}$ to $37.4{ }^{\circ} \mathrm{C}$. Upon reaching temperatures that are beyond the scope of this range, we can talk about overcooling or overheating of worker (which does not meet the conditions of "thermal comfort").

\footnotetext{
${ }^{*}$ Corresponding author: ulchieckovmihail@mail.ru
} 
In formulating the problem was considered (and for the use of additional layers of clothing - seven-layer) five-layer plate (as the heat sinks on the other coordinates are negligible). Fields of solutions includes: a layer of skin, which consists in turn of the layers: subcutaneous fat (thickness $\Delta_{1}$ ), dermis (thickness $\Delta_{2}$ ), the epidermis (thickness $\Delta_{3}$ )), the air gap between human skin and clothing $\left(\Delta_{4}\right)$, and as an external heat insulator - clothing $\left(\Delta_{5}\right)$. Skin body cover adjoins as the outer layer to the main part of person, which constant temperature. On the external surface of clothing the heat exchange with the environment where the temperature $T_{A}=$ const by natural convection.

The solution to this problem is reduced to the calculation of skin surface temperature $T_{S}$ of the worker, which will determine the "comfort" of the thermal regime.

The mathematical model of the investigated process is a system of five equations of heat conduction with boundary and initial conditions given below.

The mathematical formulation of the problem:

$$
\left\{\begin{array}{l}
\rho_{1} c_{1} \frac{\partial T_{1}}{\partial t}=\lambda_{1} \frac{\partial^{2} T_{1}}{\partial x^{2}}, 0<x<x_{1} \\
\rho_{2} c_{2} \frac{\partial T_{2}}{\partial t}=\lambda_{2} \frac{\partial^{2} T_{2}}{\partial x^{2}}, x_{1}<x<x_{2} \\
\rho_{3} c_{3} \frac{\partial T_{3}}{\partial t}=\lambda_{3} \frac{\partial^{2} T_{3}}{\partial x^{2}}, x_{2}<x<x_{3} \\
\rho_{4} c_{4} \frac{\partial T_{4}}{\partial t}=\lambda_{4} \frac{\partial^{2} T_{4}}{\partial x^{2}}, x_{3}<x<x_{4} \\
\rho_{5} c_{5} \frac{\partial T_{5}}{\partial t}=\lambda_{5} \frac{\partial^{2} T_{5}}{\partial x^{2}}, x_{4}<x<L
\end{array}\right.
$$

Here $\rho_{i}, \lambda_{i}, c_{i}-$ the density, thermal conductivity and specific heat of the material system of $i$-layer, $T i$ - current temperature value $(i=1 \ldots 5)$.

On the left border of the system (at $x=0$ ) is accepted the condition of constancy of the main body part of worker temperature (boundary conditions of the first kind). On right boundary is accepted boundary condition of the third kind, taking into account the heat transfer from the outside to worker environment - the room air. At separation boundaries between the layers were written the conditions of the fourth kind. There is considered the radiation from the skin.

The initial and boundary conditions:

$$
\begin{aligned}
& \begin{array}{l}
x=0: \quad T=T_{1}, T_{1}=\text { const } ; \\
x=x_{1}: \quad \lambda_{1} \frac{\partial T_{1}}{\partial x}=\lambda_{2} \frac{\partial T_{2}}{\partial x}, T_{1}=T_{2} ; \\
x=x_{2}: \quad \lambda_{2} \frac{\partial T_{2}}{\partial x}=\lambda_{3} \frac{\partial T_{3}}{\partial x}, T_{2}=T_{3} ; \\
x=x_{3}: \quad \lambda_{3} \frac{\partial T_{3}}{\partial x}=\lambda_{4} \frac{\partial T_{4}}{\partial x}+\varepsilon \sigma\left(\left(T_{5}\right)^{4}-\left(T_{4}\right)^{4}\right), T_{3}=T_{4} ; \\
x=x_{4}: \quad \lambda_{4} \frac{\partial T_{4}}{\partial x}=\lambda_{5} \frac{\partial T_{5}}{\partial x}, T_{4}=T_{5} ; \\
x=L: \quad \lambda_{5} \frac{\partial T_{5}}{\partial x}=\alpha\left(T_{L}-T_{A}\right) ; \\
t=0: \quad T_{1}=T_{1}^{0}, T_{2}=T_{2}^{0}, \ldots \ldots, T_{x 1}=T_{x 1}^{0}, 0<x<x_{3} ; \\
\quad T=T_{0}^{a}, x_{3}<x<x_{4} ; \\
\quad T=T_{0}^{c l}, x_{4}<x<L ;
\end{array}
\end{aligned}
$$

Here $\alpha$ - heat transfer coefficient, $\varepsilon$ - reduced emissivity surface of human skin, $\sigma$ Stefan-Boltzmann constant. 
The heat transfer coefficient was by criteria expressions for conditions of natural convection near a flat wall [5]:

$$
G r=\frac{\beta \cdot l^{3} \cdot g \cdot\left(T_{L}-T_{B}\right)}{v}
$$

Here $G r$ - the number of Grazgof, $l$ - a characteristic size (height of a man), $v$ kinematic viscosity coefficient (air), $\beta$ - the temperature coefficient of volume expansion of the air.

In laminar flow the Nusselt number for air is defined by the relation $\left(10^{-3}<G r^{*} P r<5^{*}\right.$ $\left.10^{2}\right)[6]:$

$$
N u=0,46 \cdot G r^{0,25}
$$

If the transitional flow regime $\left(5 * 10^{2}<G r * \operatorname{Pr}<2 * 10^{7}\right)$ [6]:

$$
N u=0,46 \cdot G r^{0,25}
$$

If the turbulent flow regime $\left(G r * \operatorname{Pr}>2 * 10^{7}\right)[6]$ :

$$
N u=0,133 \cdot G r^{0,33}
$$

Where from $[6,7]$ :

$$
\alpha=\frac{N u \cdot \lambda}{l}
$$

The system of differential equations with appropriate initial and boundary conditions is solved by finite difference method, using an algorithm [8,9] developed for solving heat transfer problems in the areas of multi-layer discontinuous thermal conductivity.

At the solution of the problem the temperature dependence of thermal characteristics of materials and layer materials are not taken into consideration, since the latter was only a change from $1 \mathrm{~K}$ to $10 \mathrm{~K}$.

Also assumed, the object is stationary (no additional internal heat).

\section{Results of numerical modeling}

At the modelling $T_{A}$ varies in real possible range (from $277 \mathrm{~K}$ to $304 \mathrm{~K}$ ) the thickness of the outer insulation (from $1 * 10^{-3} \mathrm{~m}$ to $5 * 10^{-3} \mathrm{~m}$ ).

$$
\begin{aligned}
& \lambda_{1}=0,2 \mathrm{Bm} / \mathrm{M} \cdot \mathrm{K}, \lambda_{2}=0,45 \mathrm{Bm} /{ }_{M} \cdot \mathrm{K}, \lambda_{3}=0,21 \mathrm{Bm} / \mathrm{M}_{M} \cdot \mathrm{K}, \lambda_{4}=0,024 \mathrm{Bm} / \mathrm{M} \cdot \mathrm{K}, \\
& \lambda_{5}^{\text {wool }}=0,03 \mathrm{Bm} / \mathrm{M} \cdot \mathrm{K}, \lambda_{5}^{\text {cotton }}=0,05 \mathrm{Bm} / \mathrm{M} \cdot \mathrm{K}, \lambda_{5}^{\text {dpbf }}=0,0097 \mathrm{Bm} / \mathrm{M} \cdot \mathrm{K} \\
& \rho_{1}=850 \mathrm{k} 2 / \mathrm{M}^{3}, \rho_{2}=1000 \mathrm{k} 2 / \mathrm{M}^{3}, \rho_{3}=1200 \mathrm{kz} / \mathrm{M}^{3}, \rho_{4}=1,2 \mathrm{kz} / \mathrm{M}^{3}, \\
& \rho_{5}^{\text {wool }}=120 \mathrm{~K} 2 / \mathrm{M}^{3}, \rho_{5}^{\text {cotton }}=100 \mathrm{~K} 2 / \mathrm{M}^{3}, \rho_{5}^{\text {dpbf }}=161 \mathrm{k} 2 / \mathrm{M}^{3} \\
& c_{1}=2250 \text { Дж } / \text { кг } \cdot K, c_{2}=3200 \text { Дж } / \text { кг } \cdot K, c_{3}=3600 \text { Дж } / \kappa 2 \cdot K, c_{4}=1005 \text { Дж } / \text { кг } \cdot K \text {, } \\
& c_{5}^{\text {woll }}=2260 \text { Дж } / \kappa 2 \cdot K, c_{5}^{\text {cotton }}=1200 \text { Дж } / \kappa 2 \cdot K, c_{5}^{\text {dpbf }}=1380 \text { Дж } / \kappa 2 \cdot K .
\end{aligned}
$$

The thicknesses of the layers of skin accepted in accordance with [7]:

$$
\Delta_{1}=0,013 m, \Delta_{2}=0,0005 m, \Delta_{3}=0,001 \mathrm{~m}
$$

Typical initial temperatures: 


$$
T_{0}^{c l}=301 K, T_{0}^{a}=303 K, T_{0}^{x 1}=307 .
$$

The duration of the modeled process chosen within the limits: $t=7000 \mathrm{c}$.

The degree of emissivity of human skin [13]:

$$
\varepsilon=0,7 \text {. }
$$

Fig. 1 shows the temperature field in the investigated system at various ambient temperatures under free convection of air surrounding the worker. As outer insulation adopted a single-layer woolen clothing $\Delta_{5}=3 \mathrm{~mm}$.

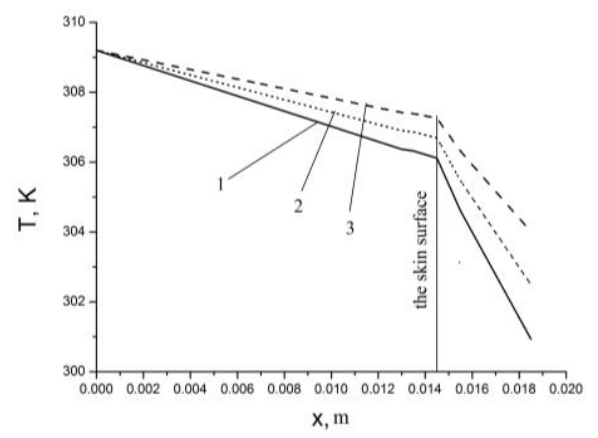

Fig. 1. The temperature distribution along the $x$ coordinate at: $1-T_{A}=291 K ; 2-T_{A}=294 K ; 3-$ $T_{A}=297 \mathrm{~K}$.

It can be seen that as the ambient temperature falls and the temperature worker surface of the skin is reduced. From the analysis of the dependence of $T(x)$ (fig. 1) and comparing them with data on the perceptions worker at different temperatures external to the environment it is possible to draw a conclusion about the possibility of assessing the numerical value of "comfortable" for worker $T_{A}$.

It is obvious that the worker does not feel the skin temperature of the body and senses the intensity of heat removal from the surface - $q$. This heat flow depends on the heatinsulating properties of the clothing and the size $T_{A}$. Therefore, based on the obtained results (fig. 1) we can conclude that the "comfortable" be $q$ values in the range of 28.2 $\mathrm{W} / \mathrm{m}^{2} \leq q \leq 42,3 \mathrm{~W} / \mathrm{m}^{2}$.

Fig. 2 shows the dependence of the temperature of the skin at time with the different $T_{A}$. It is found that the $T_{S}$ falls in time to a certain meanings appropriate to the conditions of heat exchange at the boundary $x=L$, and then does not change with increasing t.

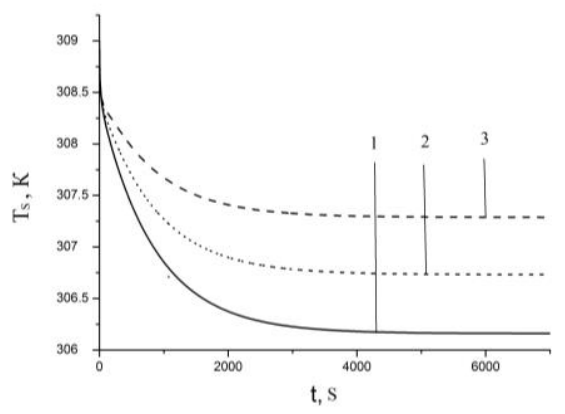

Fig. 2. $T_{S}$ dependence on time at: $1-T_{A}=291 K ; 2-T_{A}=294 K ; 3-T_{A}=297 \mathrm{~K}$.

Fig. 3 shows the dependence of temperature of skin surface of the worker on the magnitude of $T_{A}$. Based on the data obtained experimentally (comfortable for a person is 
the temperature of the skin surface from $306 \mathrm{~K}$ to $307 \mathrm{~K}$ ) [1] it can be concluded that the range of temperatures from $290 \mathrm{~K}$ to $296 \mathrm{~K}$ can be considered comfortable for the person in general. In actual practice, most likely, this interval depends essentially on the characteristics of clothing (layer thicknesses, the thermal conductivity of them), and it is from $4 K$ to $6 K$.

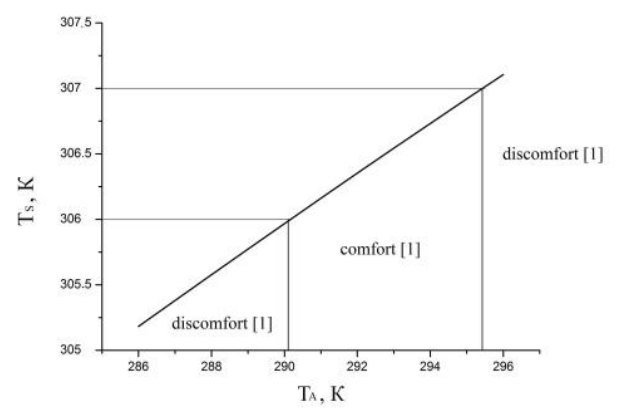

Fig. 3. The dependence of the $T_{S}$ on the ambient temperature (single layer wool clothing).

Also analyzed the dependence of the $T_{S}$ on the thickness of external insulation, at different ambient temperatures. It is found that the change in the $T_{S}$ ranges from 0.34 to $0.85 \mathrm{~K}_{5}$ with growth from $1 \mathrm{~mm}$ to $5 \mathrm{~mm}$ (Fig. 4). It is clearly seen significant as might be expected, the effect of this parameter on the value of the $T_{S}$.

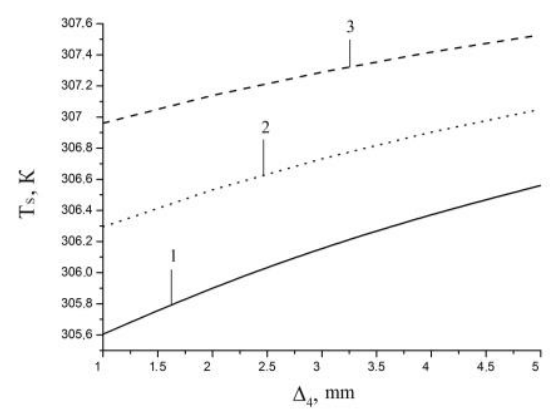

Fig. 4. The dependence of the $\mathrm{T}_{\mathrm{S}}$ on the thicknesses of the thermal insulation: $1-T_{A}=291 \mathrm{~K} ; 2-$ $T_{A}=294 \mathrm{~K} ; 3-T_{A}=297 \mathrm{~K}$.

Fig. 5 shows the relationship "comfortable" [1] of the room temperature and the thickness of the the thermal insulation layer. This makes it possible to evaluate the usefulness of a particular clothing at work in industrial environments.

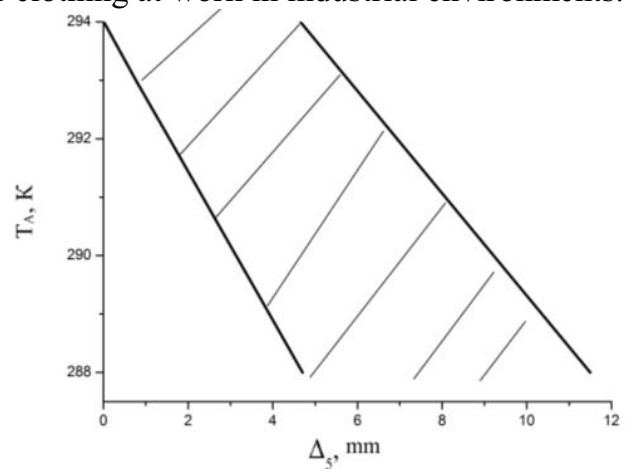

Fig. 5. The dependence of the thickness of the insulation (clothing) from the "comfortable" $T_{A}$. 
In addition to the influence of the thickness of the individual layers the thermal insulation as well the impact of the number of layers of clothing and their thermal characteristics to "comfortable" temperature $T_{A}$ is investigated. Thus in fig. $6 T_{S}$ dependence on the ambient temperature is considered, where the external insulation system appear the "cotton inner wear (thickness $1 \mathrm{~mm}$ ) - air layer (thickness $1 \mathrm{~mm}$ ) - woolen outer layer (thickness $3 \mathrm{~mm}$ )". It can be seen that the interval comfortable ambient temperature is changed from $288 \mathrm{~K}$ to $294 \mathrm{~K}$.

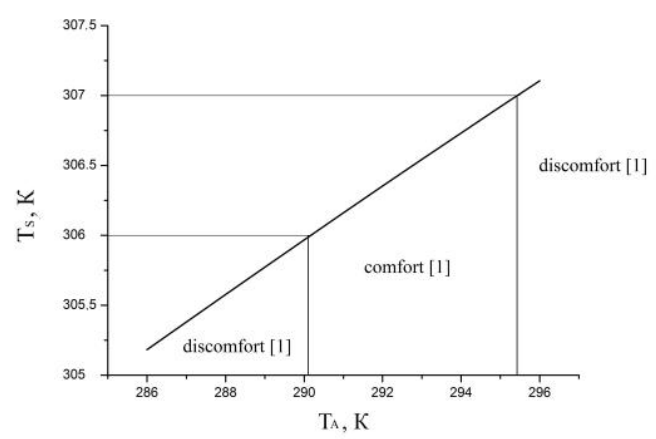

Fig. 6. The dependence of the $T_{S}$ on the ambient temperature (double-layer clothing - cotton and wool).

Fig. 7 shows a similar relationship for the system - "cotton inner wear (thickness $1 \mathrm{~mm}$ ) - air layer (thickness $1 \mathrm{~mm}$ ) - basic-fleecy fabrics layer (thickness $3 \mathrm{~mm}$ )". Due to the fact that the thermal conductivity of this material is substantially less than the thermal conductivity of wool, comfortable temperature range is from $280 \mathrm{~K}$ to $288 \mathrm{~K}$.

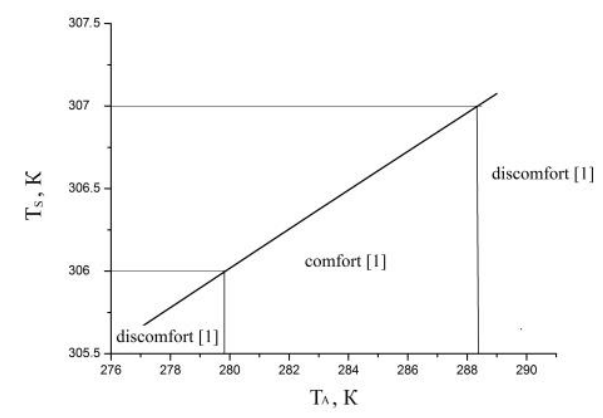

Fig. 7. The dependence of the $T_{S}$ on the ambient temperature (double-layer clothing - cotton and basic-fleecy fabrics).

\section{The main results and conclusions}

1. Heat conduction problem for the system "heating facility - the thermal insulation layer - the external environment" is solved, taking into account the natural convection in the outer clothing the border and radiation at the human skin.

2. Depending on the temperature of working surface of the skin from the outside air temperature at different thicknesses of the layers of external insulation were obtained at different sets clothing and different thermal characteristics of materials. 
3. Insulation thickness corresponding to the "comfortable" ambient temperatures were set.

4. Ambient temperature, corresponding to the conditions of "comfort" for a variety of clothing options in natural convection mode are shown.

The work was supported by the Russian Federation President's grant (NSH project 7538.2016.8).

\section{References}

1. V. N. Platova, Biologia 8 (High School, Moscow, 2008)

2. P. Domingues, P. Carreira, R. Vieira, W. Kastner, Matec Web of Conferences 45, 6 (2016)

3. M Wallance, R. McBride., P. Mhaskar, J. House, T. Salsbury, Chem. Eng. Sci. 69, 45 (2012)

4. M. Taleghani, M. Tenpierik, A. Dobbelsteen, Solar Energ. 103, 108 (2014)

5. Robert E. Simons, Electroning cooling 6 (2001)

6. F. P. Incropera, D. P. DeWitt Fundamentals of Heat and Mass Transfer (John Wiley and Sons, NY, 1985)

7. F. Xu, T. J Lu, K. A., Sef. Acta Mech. S. 24 (2008)

8. O.V. Vysokomornaya, G.V. Kuznetsov, P.A. Strizhak, Rus. J. Ph. Ch. B 5 (2011)

9. V.L. Strakhov, A.N. Garashchenko, G.V. Kuznetsov, V.P. Rudzinskii, Comb., Exp. Sh. W. 37 (2001)

10. I.K. Kikoin Tables of physical quantities (Atomizdat, Moscow, 1976)

11. A.P. Babichev, A.P. Babushkin, A.M. Bratkovsky Physical values, (Eneroatomizdat, Moscow, 1991)

12. M.V. Nazarova, S. Yu. Boyko, Modern problems of s. and ed. 5 (2009)

13. U. Kukelev, A. Ustinov, Resources and Technology 3 (2005) 